\title{
SCREENING OF HIV ANTIBODIES BEFORE MEDICOLEGAL AUTOPSIES
}

\author{
Sangeetha Ranganathan1, Gokula Ramanan², Saravanan Ranganathan ${ }^{3}$, Mohan Kumar $^{4}$
}

${ }_{1}^{1}$ Assistant Professor, Department of Forensic Medicine, Govt. Mohan Kumaramangalam Medical College Hospital, Salem, Tamilnadu. ${ }^{2}$ Associate Professor, Department of Forensic Medicine, Govt. Mohan Kumaramangalam Medical College Hospital, Salem, Tamilnadu. ${ }^{3}$ Tutor, Department of Pharmacology, Annapoorana Medical College and Hospital, Salem, Tamilnadu. ${ }_{4}^{4}$ Assistant Professor, Department of Dental Surgery, Govt. Mohan Kumaramangalam Medical College and Hospital, Salem, Tamilnadu.

\section{ABSTRACT}

\section{BACKGROUND}

Acquired Immunodeficiency Syndrome (AIDS) is a chronic, life-threatening condition caused by Human Immunodeficiency Virus (HIV). The post-mortem examination room is the place where infection can spread to persons performing autopsy. The persons involved in autopsy are having a very high risk of various injuries and infections. Therefore, screening of HIV is necessary in routine medico-legal autopsies to prevent spread of infection to forensic personnel.

\section{OBJECTIVES}

The objectives of the present study were to determine the incidence of HIV infection in deceased whose HIV status was not previously known, to create the awareness among forensic personnel and to know the importance of HIV antibody screening in routine medico-legal autopsies.

\section{MATERIALS AND METHODS}

The study was conducted on 486 routine autopsy cases at Rajiv Gandhi Government General Hospital. The samples were tested for HIV antibodies using SD Bioline HIV-1/2 3.0 - a rapid immunochromatography assay test kit to detect the presence of HIV-1 and/or HIV-2 antibodies. Samples yielding HIV seropositive were confirmed by Alere Determine ${ }^{\mathrm{TM}}$ HIV $1 / 2$ antibody test - an immunochromatography test to detect HIV-1 and/or HIV-2 antibodies.

\section{RESULTS}

Out of 486 samples tested for HIV antibodies, 4 samples gave positive result and all the four cases were positive only for HIV-1. The positive cases were not previously known to have HIV infection and all 4 positive cases were male. When looked into the cause of death, among the 4 positive cases 2 cases (50\%) had homicidal cause. This shows that screening of HIV infection is essential in community where crime rate is high.

\section{CONCLUSIONS}

HIV antibodies were identified in 4 cases in whom the HIV status was not previously known. Though the number of seropositive samples was not significant, it shows that there is high chance of occupational transmission of HIV infection to forensic per sonnel in autopsy room. Therefore, screening of HIV antibodies is of great importance in routine autopsy cases.

\section{KEYWORDS}

HIV, Immunochromatography Assay, Forensic Personnel.

HOW TO CITE THIS ARTICLE: Ranganathan S, Ramanan G, Ranganathan S, et al. Screening of HIV antibodies before medicolegal autopsies. J. Evolution Med. Dent. Sci. 2016;5(53):3506-3510, DOI: 10.14260/jemds/2016/809

\section{INTRODUCTION}

Acquired Immunodeficiency Syndrome (AIDS) is caused by Human Immunodeficiency Virus (HIV). HIV is a disorder of the immune system, in which there is a breakdown of defence mechanism against infection, which leaves the person susceptible to the life-threatening infectious diseases including unusual malignancies. ${ }^{1}$ It is estimated that about 14,000 HIV infections occur everyday around the world approximately and out of these $90 \%$ of these are in developing countries. ${ }^{2}$ The post-mortem examination room is the place where infection can spread to persons who are performing autopsy.

Financial or Other, Competing Interest: None.

Submission 23-05-2016, Peer Review 18-06-2016,

Acceptance 23-06-2016, Published 02-07-2016.

Corresponding Author:

Dr. Sangeetha Ranganathan,

Assistant Professor,

Department of Forensic Medicine,

Govt. Mohan Kumaramangalam Medical College Hospital,

Salem, Tamilnadu, India.

E-mail:drsangimohan@gmail.com

DOI: 10.14260/jemds/2016/809
These Forensic personnel are involved in examination of homosexuals and drug abusers are at high risk of being infected by HIV than common people. Forensic experts are exposed not only to scalpels, needles, but also to the bones, body fluids and tissues of dead bodies everyday. ${ }^{3}$

Testing for HIV in the autopsy room has not been done routinely because samples to be tested need a special equipped laboratory, well trained technician and also more time is needed to obtain the results. Therefore, a simple, reliable and rapid means for detecting the antibodies to HIV infection is needed and this can be useful for screening in the autopsy rooms. ${ }^{4}$ Only limited data is available regarding the occupational transmission of the HIV from the corpses to the persons who are engaged directly or indirectly in the autopsy procedures and other individuals who handle the dead bodies at various stages of decomposition. Testing HIV antibodies during autopsies has been useful not only for assessing the risk to the mortuary workers, but also useful for the epidemiological studies. 5 The applicability of the tests for detecting antibodies to HIV in autopsy samples depends on the post-mortem stability of the antibodies as well as on the sensitivity of the screening tests. ${ }^{6}$ 
Autopsy screening efficiently reveals the true incidence in groups, where refusal may be common. This study enables to identify HIV status of the deceased whose HIV status was unknown previously, because it is not practical or costeffective to take full universal precaution with every autopsy. ${ }^{7}$ The objectives of the study are to study the incidence of HIV in routine autopsy cases, to create awareness among the doctors doing post-mortem and the mortuary workers, to diagnose the clinically undetected HIV cases and to determine the safety of forensic personnel involved in autopsies in relation to preautopsy testing for HIV. The purpose of this study is to determine whether autopsies of the corpses, which have been presumed to be low risk groups are safe or not. Thus, we conducted a study to identify the seroprevalence of these viruses in a high risk forensic autopsy population.

\section{MATERIAL AND METHODS}

The study was conducted at the Institute of Forensic Medicine, Chennai-3. The study sample consists of 486 routine autopsy cases at Rajiv Gandhi Government General Hospital for a period of 1 year. The study was carried out after obtaining approval by Institutional Ethical Committee. Blood samples were collected from a sum of 486 cases autopsied at Rajiv Gandhi Government General Hospital. The blood samples were collected via cardiac chamber or femoral vessel at the time of autopsy. The samples were tested for HIV and the identity of the individual was blinded. None of the cases had a previous known HIV status.

The individual's data such as demographics, cause of death, post-mortem interval and positivity for the type of HIV (HIV-1 and/or HIV-2) are recorded. The samples were tested using an enzyme immunoassay using SD Bioline HIV-1/2 3.0 Rapid test kits to detect the presence of HIV-1 and HIV-2 antibodies. The test procedure was performed according to the protocols supplied by the manufacturers. Samples yielding reactive results were confirmed by Alere Determine ${ }^{\mathrm{TM}} \mathrm{HIV} 1 / 2$ method, which detects HIV-1, HIV-2 antibodies. The samples were tested anonymously for study purpose; hence, the samples were collected without informed consent. Samples are anonymous, if it is impossible under any situation for anyone to identify the source of the sample.

\section{SD Bioline HIV-1/2 3.0}

SD BIOLINE HIV-1/2 3.0 Rapid test kit is an immunechromatographic test for the detecting antibodies to all isotypes (IgM, IgG) specific to HIV-1 and HIV-2 concurrently in human serum, plasma or whole blood qualitatively. It has $100 \%$ Sensitivity and $99.8 \%$ Specificity. The SD BIOLINE HIV1/2 3.0 Rapid test has a membrane strip, which has two test band regions. The kit has test band 1 (HIV-1) precoated with recombinant HIV 1 capture antigen (gp24, p41), test band 2 (HIV-2) precoated with recombinant HIV2 capture antigen (gp36) and a control band C. The recombinant HIV-1/2 antigen (gp24, p41 and gp36) gold conjugate and the sample move chromatographically to the test region (T) and develop a visible line as the antigen - antibody - antigen gold particle complex with a high degree of specificity and sensitivity. Test lines and control line are not visible before applying any sample. The control line serves as procedural control. Control should appear if test procedure is performed properly.

\section{PROCEDURE}

After opening the foil pouch the test device is placed on a dry, clean, bright, flat surface. With the help of capillary pipette, 20 $\mu \mathrm{l}$ of blood specimen which is taken directly from the cardiac vessel or femoral vessel puncture is added into the sample well (Indicated with the letter ' $S$ ') in the test device, then four drops of assay diluent are added into the sample well. If the test is in progress, a purple colour band moves across the result window, which is in the centre of the test device. Interpretation of the test results was done within 5-20 minutes.

\section{Interpretation}

A colour band that appears in the control line (C) signifies that the test is properly working. Colour bands that appear in the test line 1 and test line 2 of the result window are considered positive for HIV 1 and HIV 2 respectively. The presence of two lines - control line (C) and test line 1 (1) within the test device designates a positive result for HIV 1 (Figure 1). The presence of two lines as control line (C) and test line 2 (2) within the test device designates a positive result for HIV 2. The occurrence of three lines as control line (C) and test line 1 (1) and test line 2 (2) within the test device designates a positive result for both HIV-1 and HIV-2. Absence of control line (C) within the result window specifies an invalid result. The instructions are followed incorrectly or the test sample may have been deteriorated. Therefore, the specimen should be re-tested.

\section{Limitations of the Test}

To diagnose AIDS, Immunochromatography testing alone cannot be used even if the antibodies against HIV-1 and/or HIV-2 are present in a deceased specimen. At the same time, negative result does not exclude the possibility of HIV-1 and/or HIV-2 infection. This is because the specimen may contain low levels of antibodies to HIV-1 and/or HIV-2.

\section{Specifications of Alere Determine ${ }^{\mathrm{TM}} \mathrm{HIV} 1 / 2$}

The AlereDetermine ${ }^{\mathrm{TM}} \mathrm{HIV}-1 / 2$ is an in vitro, qualitative immunochromatography test which is visually read for the detection of HIV-1 and HIV-2 antibodies in human serum, whole blood or plasma. It has $100 \%$ Sensitivity and $100 \%$ specificity.

\section{PROCEDURE}

The protected foil covering the test card was removed; $50 \mu \mathrm{L}$ of sample was applied to the sample pad, followed by a drop of chase buffer after 1 minute. The results were read after a minimum interval of 15 mins. When a sample is added to the sample pad, it migrates through the conjugate pad; it mixes with the selenium colloid-antigen conjugate. This migrates through the solid phase to the immobilized recombinant antigens and synthetic peptides at the window site. If HIV-1 and/or HIV-2 antibodies are present in the sample, the antibodies bind to the antigen as well as to the antigenselenium colloid at the patient window forming a red line (Figure 2). Absence of red line signifies absence of antibodies to HIV-1 and/or HIV-2. A control bar is incorporated in the assay device to insure assay validity.

\section{Limitations of the Test}

The Alere DetermineTM HIV-1/2 detects HIV-1 and HIV-2 antibodies in whole blood, serum, plasma. Other body fluids or 
pooled specimens may not give accurate results. A negative result will not ignore the possibility of HIV infection. False negative results occur if Antibody levels are low, Infection with a variant of the virus, specimen handling conditions which result in loss of HIV antibody multivalency. Whole blood or plasma specimen containing anticoagulants other than EDTA may give incorrect results.

\section{RESULTS}

Of the 486 samples tested, HIV antibodies were detected in 4 samples using SD BIOLINE HIV-1/2 3.0 Rapid test kit. The 4 positive samples were tested again by rapid assay Alere Determine $^{\mathrm{TM}}$, which were also positive for HIV-1. Data such as demographics, cause of death, post-mortem interval and positivity for HIV-1 and or HIV-2 are recorded.

Out of the 4 positive samples, all were positive for HIV-1 and none were positive for HIV-2. All four HIV positive cases were not previously known to have HIV infection. Presence of two murder cases among the four HIV positive cases indicates that HIV positive cases are clustered in homicide cases.

Males occupy predominant number of cases, accounts for about $85.8 \%$ of study sample, whereas females constitute only $14.2 \%$ of the study sample. Among the positive samples all were male $(100 \%)$, none of the samples were positive among female indicating that seroprevalence is higher in males (Table 1).

Among 486 cases analysed, predominant number of cases (45.3\%) falls under age group between 21 and 40 years followed by age group between 41 and 60 years (31.3\%). In this study, out of four cases two cases were positive in the age group between 61-80 years, indicating higher seroprevalence was in the age group between 61 and 80 years (Table 2).

When looked into the cause of death among the positive cases, the two cases were homicide (50\%). Out of the total eleven murder cases in this study, two were positive (18.1\%). This shows that HIV screening is of great importance among the community, where the crime rate is high. Homicide victims in our study showed a relatively higher prevalence of HIV-1, infections compared with other manner of death.

\begin{tabular}{|c|c|c|c|c|}
\hline Sex & $\begin{array}{c}\text { No. of } \\
\text { Sample }\end{array}$ & $\begin{array}{c}\text { \% of } \\
\text { Samples }\end{array}$ & $\begin{array}{c}\text { No. of } \\
\text { Positive } \\
\text { Cases }\end{array}$ & $\begin{array}{c}\text { \% of } \\
\text { Positive } \\
\text { Cases }\end{array}$ \\
\hline Male & 417 & 85.8 & 4 & 0.719 \\
\hline Female & 69 & 14.2 & 0 & 0 \\
\hline Total & $\mathbf{4 8 6}$ & $\mathbf{1 0 0}$ & $\mathbf{4}$ & $\mathbf{0 . 8 2 3}$ \\
\hline \multicolumn{2}{|r|}{ Table 1: Sex Distributions among the Study Sample } \\
\hline
\end{tabular}

\begin{tabular}{|c|c|c|c|c|}
\hline $\begin{array}{l}\text { Sl. } \\
\text { No. }\end{array}$ & $\begin{array}{c}\text { Age } \\
\text { Distribution }\end{array}$ & $\begin{array}{c}\text { No. of } \\
\text { Sample }\end{array}$ & $\begin{array}{l}\text { \% of Case } \\
\text { Occupancy }\end{array}$ & $\begin{array}{c}\text { No. of } \\
\text { Positive } \\
\text { Cases }\end{array}$ \\
\hline 1. & $\begin{array}{c}\text { Age } 0-20 \\
\text { years }\end{array}$ & 41 & 8.4 & 0 \\
\hline 2. & $\begin{array}{c}\text { Age } 21-40 \\
\text { years }\end{array}$ & 220 & 45.3 & 1 \\
\hline 3. & $\begin{array}{c}\text { Age } 41-60 \\
\text { years }\end{array}$ & 152 & 31.3 & 1 \\
\hline 4. & $\begin{array}{c}\text { Age } 61-80 \\
\text { years }\end{array}$ & 68 & 14 & 2 \\
\hline 5. & $\begin{array}{c}\text { Age } 81-100 \\
\text { years }\end{array}$ & 5 & 1 & 0 \\
\hline 6. & Total & 486 & 100 & 4 \\
\hline
\end{tabular}

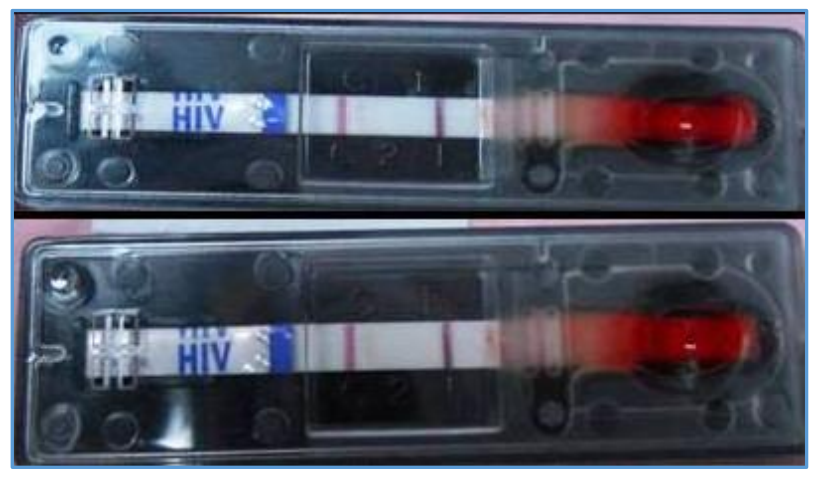

Fig. 1: HIV-1 Positive using SD BIOLINE HIV-1/2 3.0 Rapid Test Kit

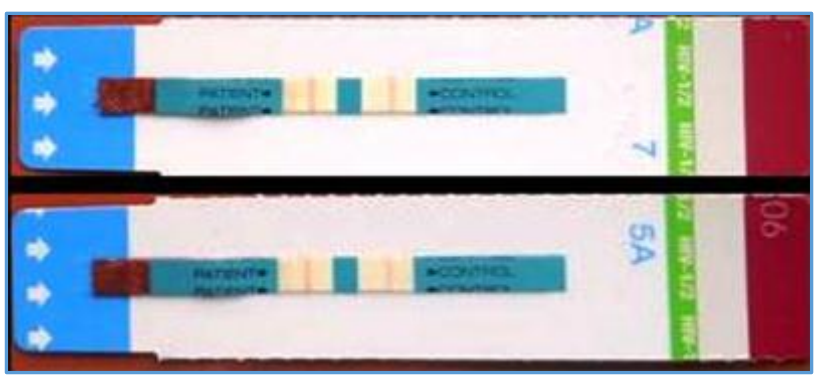

Fig. 2: HIV-1 Positive using Alere Determine $^{T M} \mathrm{HIV}-1 / 2$

\section{DISCUSSION AND CONCLUSION}

A person infected with HIV may die of an unrelated cause. In those individuals, there is no clear-cut evidence of HIV status. This occurrence of new cases helps us to supervise HIV epidemic in the country. HIV antibodies testing in autopsies have also been valuable for epidemiological purposes. ${ }^{8,9}$ This information also helps us to create or modify the awareness program to educate the general population and high risk community who are vulnerable to HIV infection. Consistent tests may also be needed to reduce the occupational health hazards in the mortuary, because the HIV may survive for several days in post-mortem samples. ${ }^{10}$

Medicolegal autopsies include fatal traffic accidents, sudden death, homosexuals and drug addicts with a high risk of HIV-infection. ${ }^{11}$ Hence, HIV-testing in medicolegal autopsies would be an essential tool to find 'hidden' HIV carriers. ${ }^{12,13}$ When the forensic pathologists conduct autopsy on deadbodies irrespective of the stage of decomposition, there is high chance of exposure to various infectious organisms in the body fluids and tissues.

The studies conducted prospectively have assessed that approximate risk of infection by HIV after a percutaneous needle injury is at a rate of $0.3 \%{ }^{14}$ In the context of an autopsy, it is important that not only blood but also other body fluids that are highly infectious like amniotic fluid, pleural fluid, seminal fluid, pericardial fluid, peritoneal fluid, vaginal fluid and cerebrospinal fluid. Rupture of the surgical glove occurs in about $9 \%$ of autopsy. About 33\% of glove puncture goes undetected by the pathology personnel, which can expose the previous injury in the hand to come in contact with infected blood for a long time. ${ }^{15}$

Coleman et al did a study to detect antibodies to the Retrovirus in presumably healthy San Franciscans who died unexpectedly. Of the 121 samples tested for antibodies to HIV, 23 cases were positive for HIV, which was very high than other voluntary screening programs. ${ }^{16}$ Vitreous humor is reliable for 
testing antibodies to HIV up to 34 hours post-mortem and blood at least up to 58 days were frequently positive for HIV. ${ }^{11}$ Viable HIV was isolated from the cultured blood sample on $17^{\text {th }}$ day of autopsy, pleural fluid on 14th day of autopsy and pericardial fluid on $16^{\text {th }}$ day of autopsy. There is no time period when autopsy can be performed without risk of infection to HIV. Therefore, delay in performing post-mortem will not abolish the risk of HIV infection. ${ }^{17}$ Zehner et al conducted the study to detect HIV antibodies in post-mortem blood samples; 456 samples were collected and tested using the HIV-1/HIV-2 Test pack, among which 21 cases were proved to be positive and it was confirmed by Western blot. The study concludes that this HIV-Test pack gives proper results to HIV antibodies in whole blood. All these studies show the importance of HIV antibody testing during autopsy. 18

A simple, reliable and rapid test to detect HIV infection can be useful in the mortuary, because it is not possible always to get the complete and correct information about all of the risk factors before commencing the postmortem, because of the social and cultural restrictions. Therefore, the lack of a known history of such a risk factor does not equate with then on existence of such risk factor. Hence, testing for HIV in medicolegal autopsies will identify carriers in whom HIV status was not previously known.

In our study the four positive cases out of 486 cases were not known to have HIV, which means they are clinically undetected for HIV antibodies. This indicates that people at high risk are clustered in the medico-legal autopsy series. Furthermore, it has been demonstrated that extensive haemolysis of cadaveric blood does not interfere with ELISA or Western blot analysis of HIV seropositivity. In general, proteins such as the globulins that comprise antibodies may not be affected by postmortem decomposition, haemolysis or bacterial contamination.6,10 In this study, it was estimated that the postmortem interval was ranging from 8 hours to 26 hours for detection of HIV antibodies.

The present study concludes that testing of HIV in medicolegal autopsies is a convenient and effective method in monitoring the surveillance of HIV-infection in the general population and it can be used for epidemiological studies. It could be used along with unlinked anonymous tests from hospital and other similar patient materials. Testing for HIV may also be desired for safety reasons in mortuaries. ${ }^{19}$ In screening postmortem blood for HIV-antibodies, the present study represents that rapid assay test pack is simple, rapid, no special equipment is required, even whole blood can be used and has very high sensitivity of $100 \%$ and specificity of $99.8 \%$ and tests both HIV-1 and HIV-2.

Out of 486 subjects in this study group, 4 cases were positive for HIV and all were previously unknown seropositive cases. Though the rate of infection appears to be less than $1 \%$, it is not possible to overlook the chance of being infected precautions with every autopsy. It would, therefore, be advantageous to know a deceased HIV serological status prior to autopsy. Screening may be worthwhile in cases at high risk of HIV infection, where the HIV antibody status is not known at the time of postmortem.

\section{REFERENCES}

1. Plantier JC, Marie L, Dickerson JE, et al. A new human immunodeficiency virus derived from gorillas. Nature Medicine 2009;15:871-2.
2. Richard H. Microbiology and immunology virologychapter seven, part five. Human Immune Deficiency Virus and Aids Statistics. 2016.

3. Mehta S, Singh V, Kaur B, et al. Pre-testing screening for HIV before conducting post-mortem examinations. JK Science 2012;14(2):70.

4. Li L, Constantine N, Zhang X, et al. Determination of human immunodeficiency virus antibody status in forensic autopsy cases using a rapid and simple FDAlicensed assay. JFSCA 1993;38(4):798-805.

5. Klatt EC, Shibata D, Strigle SM. Postmortem enzyme immunoassay for human immunodeficiency virus. Archives of Path and Laboratory Medicine 1989;113(5):485-7.

6. Brazinsky JH, Kellenberger RE. Comparison of immunoglobulin analysis of antemortem and postmortem sera. American Journal of Clinical Pathology 1970;54(4):622-4.

7. Karhunen PJ, Penttila A, Kantanen ML, et al. Screening for HIV in medicolegal necropsies in Helsinki. British Medical Journal 1989;298(6681):1160.

8. Rajs J, Karlsson T, Eklund B, et al. HIV related deaths outside medical institutions in Stockholm. Forensic Science International 1989:41(3):269-80.

9. Nyberg $M$, Suni J, Haltia M. Isolation of human immunodeficiency virus (HIV) at autopsy one to six days postmortem. American Journal of Clinical Pathology 1990;94(4):422-5.

10. Puschel K, Mohsenian F, Laufs R, et al. Postmortem viability of the human immunodeficiency virus. International Journal of Legal Medicine 1991;104(2): 109-10.

11. Sharma BR, Reader MD. Autopsy room: a potential source of infection at work place in developing countries. American Journal of Infectious Diseases 2005;1(1): 25-33.

12. Thompson C, Isaacs G, Supple D, et al. AIDS: dilemmas for the psychiatrist. The Lancet 1986;327(8475):269-70.

13. Penttil A, Ahonen H, Vuori E. Deaths among the people known to the police of Helsinki to be associated with narcotic drugs in 1976-1984. Proceedings of the $9^{\text {th }}$ meeting of the Scandinavian forensic society. 1985: 109-20.

14. Henderson DK, Fahey BJ, Willy $M$, et al. Risk for occupational transmission of human immunodeficiency virus type 1 (HIV-1) associated with clinical exposures. A prospective evaluation. Annals of Internal Medicine 1990;113(10):740-6.

15. Weston J, Locker G. Frequency of glove puncture in the postmortem room. Journal of Clinical Pathology 1992;45:177-8.

16. Coleman DL, Luce JM, Wilber JC, et al. Antibody to the retrovirus associated with the acquired immunodeficiency syndrome (AIDS). Presence in presumably healthy San Franciscans who died unexpectedly. Archives of Internal Medicine 1986;146(4):713-5.

17. Douceron H, Deforges L, Gherardi R, et al. Long-lasting postmortem viability of human immunodeficiency virus: a potential risk in forensic medicine practice. Forensic Sci Int 1993;60(1-2):61-6. 
18. Zehner R, Bratzke H, Mebs D. Evaluation of a rapid assay system, HIV-1/HIV-2 test pack, abbott, to detect human immunodeficiency virus antibodies in postmortem blood. J Forensic Sci 1995;40(1):113-5.
19. MacArthur S, Schneiderman H. Infection control and the autopsy of persons with human immunodeficiency virus. American Journal of Infection Control 1987;15(4):172-7. 